\title{
VALORIZACIÓN DEL PATRIMONIO A TRAVÉS DEL TURISMO MINERO. CASO DE ESTUDIO: PARQUE MINERO DE RIOTINTO, HUELVA, ESPAÑA.
}

\section{Aquilino Delgado Domínguez}

Museo Minero de Riotinto

Fundación Río Tinto

Huelva, España

Emilio M. Romero Macías

Universidad de Huelva.

Huelva, España

\author{
María de la Cinta Regalado Ortega \\ Museo Minero de Riotinto \\ Fundación Río Tinto \\ Huelva, España
}

\section{RESUMEN}

En este trabajo se expone el caso del Parque Minero de Riotinto en la Cuenca Minera de mismo nombre en la provincia de Huelva (Andalucía, España), y como partiendo de los pasivos mineros el trabajo de rehabilitación y puesta en uso turístico lo ha convertidos en activos económicos y en un nuevo yacimiento de empleo en una zona económica muy deprimida.

Palabras Clave: Patrimonio, Riotinto, turismo, industrial, minero 


\title{
RIO TINTO MINING PARK (HUELVA, SPAIN), PRESTIGE OF THE HERITAGE THROUGH TOURISM MINING.
}

\author{
Aquilino Delgado Domínguez \\ Museo Minero de Riotinto \\ Fundación Río Tinto \\ Huelva, España \\ Emilio M. Romero Macías \\ Universidad de Huelva. \\ Huelva, España
María de la Cinta Regalado Ortega
Museo Minero de Riotinto
Fundación Río Tinto
Huelva, España

\begin{abstract}
ABTRACT
The present paper describes the case of Río Tinto mining park in mineral basin of the same name in the Province of Huelva (Andalusia, España), and as, starting from the mining liabilities the rehabilitation work and implementation in value through use the tourist has been converted into economic assets and in a new field of employment in a very depressed economic zone.
\end{abstract}

Key words: Heritage, Río Tinto, tourism, industrial and mining 


\section{INTRODUCCIÓN}

Este trabajo versa sobre la experiencia desarrollada desde hace veinte años por el Parque Minero de Riotinto (Huelva, España) en la rehabilitación del patrimonio minero y su puesta en uso turístico, iniciativa pionera en España que ha permitido convertir los antiguos “pasivos mineros” en “activos económicos” (Fernández, 2007,Pág. 20).

En 1987 Río Tinto Minera S.A., compañía que explotaba Riotinto en ese momento, ante la bajada de los precios del cobre y en una coyuntura de crisis de la minería metálica crea Fundación Río Tinto para la historia de la minería y la metalurgia, institución cultural permanente con carácter benéfico docente cuyo principal objetivo es restaurar el patrimonio minero e investigarlo dándolo a conocer. En un principio los trabajos estuvieron dirigidos a realizar un inventario catalogando los bienes atendiendo a los siguientes criterios: Identificación y descripción de los bienes muebles e inmuebles; Documentación arqueológica, documental, histórica, documental, fotográfica, ubicación y por último el estado de conservación y la necesidad de restauración. Una vez realizado esta fase se pasó a seleccionar los bienes a rehabilitar siguiendo los criterios de: autenticidad histórica, representatividad tipológica; antigüedad absoluta de la pieza o edificio en cuanto la a tipología o técnica; estado de conservación; significación histórica y por último posibilidad de gestión del bien bajo criterios de sostenibilidad.

Figura 1 Vista paisaje Minero.

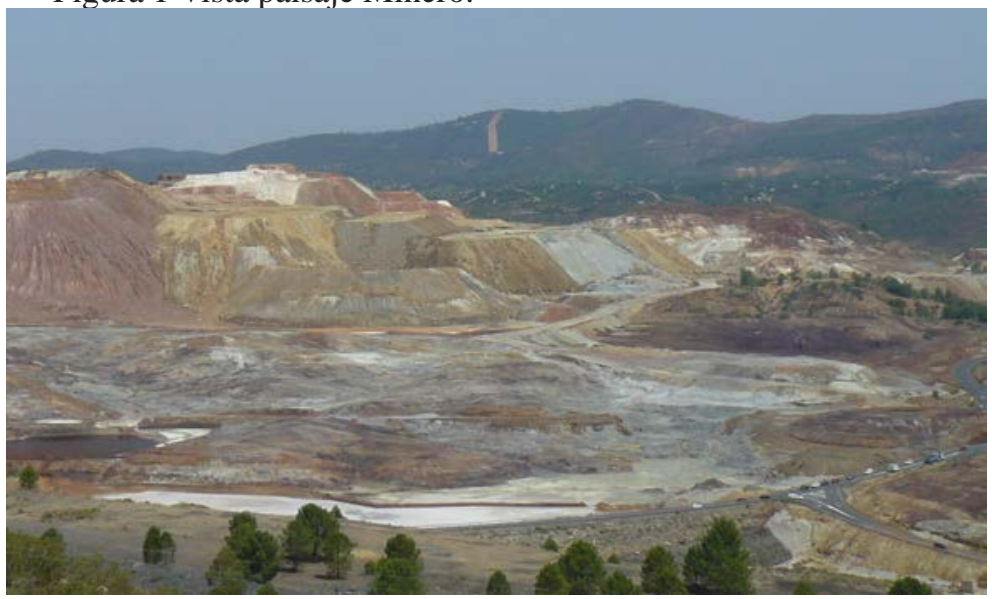

En 1992 Fundación Río Tinto crea el Parque Minero de Riotinto, objeto de este trabajo, que dinamiza y gestiona el patrimonio valorizado turísticamente, creando en una zona deprimida económicamente un nuevo yacimiento de empleo teniendo como 
referentes Iron Bridge en Gran Bretaña y Bochum en Alemania (Delgado y Regalado 2011, Pág. 499), que junto a Le Creusot en Francia son los mejores paradigmas de las nuevas concepciones desarrolladas en Europa.

\section{El Concepto de Patrimonio Minero y de Turismo Minero}

TICCIH (The International Committe for the Conservation of the Industrial Heritage) en la Carta de Nizhny Tagil sobre Patrimonio Industrial (Moscú, 17 de julio de 2003), que desarrolla la Carta Internacional sobre la Conservación y la restauración de los monumentos, conocida como Carta de Venecia de (ICOMOS 1964). El Patrimonio Minero en España, stricto sensu, se ha definido en "La Carta de El Bierzo para la Conservación del Patrimonio Industrial Minero", elevada al Consejo de Patrimonio Histórico del 27 de junio de 2008, y aprobada por el mismo. La Ley 14/2007 de 26 de noviembre de Patrimonio Histórico de Andalucía en el Título VII en el art no 65 define el Patrimonio Industrial Andaluz.

Nuestra concepción del Patrimonio Minero es todo aquel generado por la actividad minero-metalúrgica en cualquier época por lo que excedería y englobaría al industrial-minero, y en el caso que nos ocupa es aún más patente pues la Cuenca Minera de Riotinto es la zona minera con actividad continuada más antigua del mundo, teniendo documentado trabajos de extracción y transformación de los mismos para obtener metales desde el calcolítico o edad del cobre en el III milenio antes de nuestra era (Pérez, J.A., 1996, Pág. 52-56) hasta 2001, actualmente está en proyecto la reapertura de este yacimiento minero. De estos 5000 años los dos períodos más importantes de explotación han sido época romana entre los siglos II a. C. al V d. C. (Pérez, J.A., 1998, Pág. 217-218) y el período en que las minas fueron trabajadas por un consorcio de capital extranjero, principalmente británico, Río Tinto Company Limited entre 1873 y 1954 (Harvey, C.E, 1981, Pág. 314-322).

Figura 2 Paisaje industrial

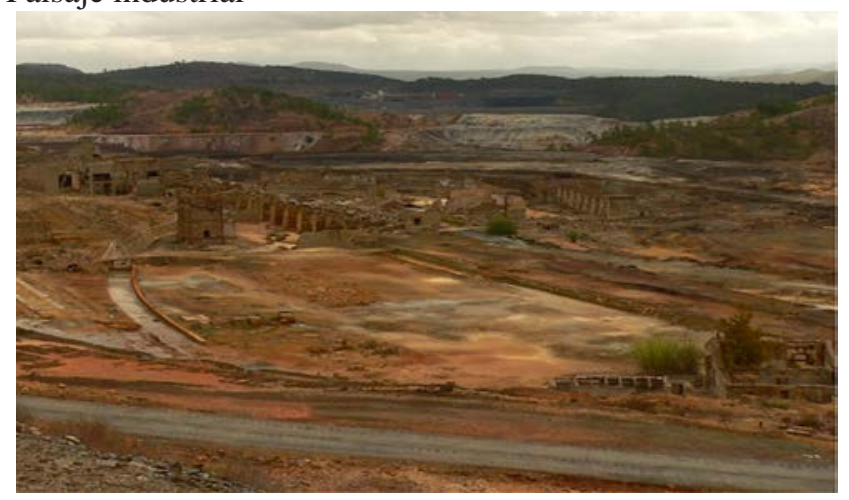


El turismo minero lo entendemos una modalidad del turismo cultural (Valenzuela et al, 2008, Pág. 231), que supone un fenómeno nuevo dentro de los productos turísticos que complementan a los destinos tradicionales, ofreciendo otras actividades (Peñalver 2004, Pág. 179), así mediante el turismo se están recuperando espacios degradados, instalaciones y actividades en desuso. Esta modalidad turística se desarrolla principalmente en zonas rurales en un territorio extenso que suele exceder el término municipal y con una tradición que se remonta a épocas históricas, cuando el patrimonio industrial se remonta sólo a los dos últimos siglos. El patrimonio y los recursos turísticos del turismo minero superan en tipologías y variedad al industrial (García y Delgado 2011, Pág. 463), pues en los espacios mineros "confluyen vertientes patrimoniales de carácter arqueológica, paisajística, etnológica, industrial, documental, artística, monumental, histórica” (Pérez y Romero 2008, Pág. 87). La crisis de las zonas mineras ha favorecido el expolio del patrimonio pues tras perder su funcionalidad las distintas instalaciones e infraestructuras pasaron a convertirse en una fuente de aprovisionamiento de materiales, otra característica de este tipo de zona es que presentan una fuerte depresión económica y social, altos índices de paro que hacen que buena parte de la población activa emigre favoreciendo el envejecimiento y la baja densidad (García y Delgado 2011, Pág. 467). El turismo minero es que ha ayudado a cambiar la imagen del territorio, pasando de ser un paisaje degradado a un paisaje cultural donde puede leerse la historia de la zona de forma diacrónica y sobre todo en un recurso útil que ayude a la recuperación económica de estas zonas degradadas (Martínez y Pérez, 1998, Pág. 51) que en definitiva no es más que valorizar su patrimonio marginado y olvidado que en realidad es buscar cualquier estrategia válida que ayude a la recuperación de las zonas minera deprimidas (Llurdés, 1999, Pág. 148).

\section{Situación y descripción geográfica y geológica de la Cuenca Minera de Riotinto.}

La Cuenca Minera de Riotinto está ubicada al NE de la provincia de Huelva, limitando con la de Sevilla a levante. Está compuesta por siete pueblos: Berrocal; El Campillo; La Granada de Río Tinto, Minas de Riotinto, Nerva y Zalamea la Real que con una superficie de $622,71 \mathrm{~km}^{2}$ supone el 6,13\% del total provincial. Esta comarca está drenada por dos ríos Odiel que la cruza de NE a SO y Tinto de Norte a Sur, siendo este río de aguas ácidas de color bermejas ecosistema único en el mundo quien da nombre a esta zona. 
Figura 3. Situación geográfica de la cuenca Minera de Riotinto.

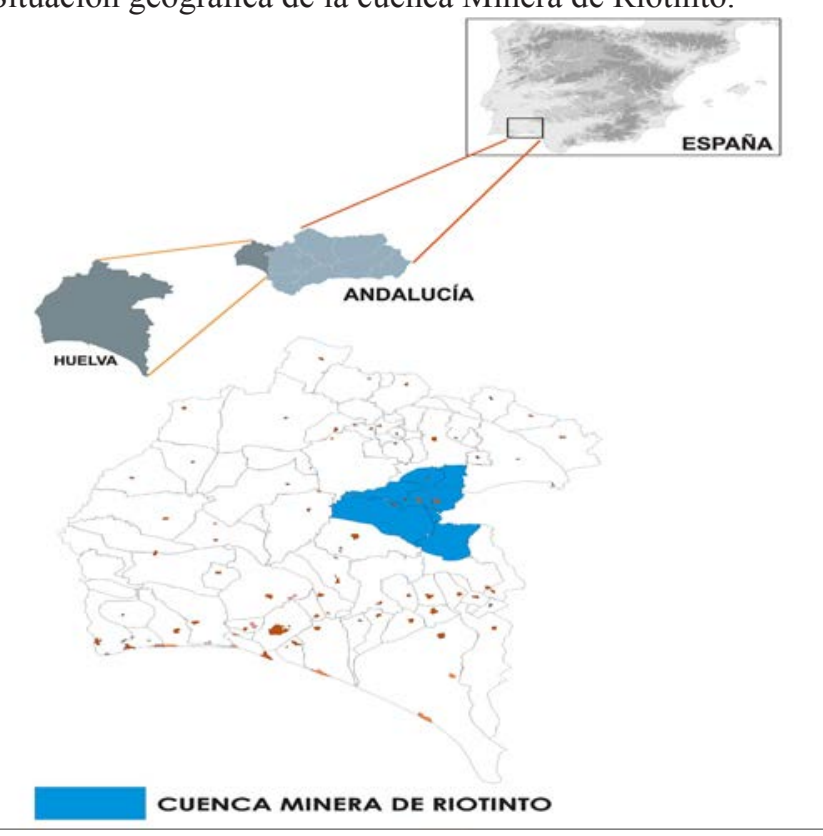

Elaboración propia.

En la FPI afloran rocas del Paleozoico Superior (Devónico Medio-Carbonífero Superior), que reflejan los cambios acontecidos en la cuenca sudportuguesa desde una situación preorogénica hasta la etapa sinorogénica de la evolución varisca. La fase preorogénica estuvo caracterizada por una sedimentación marino-somera dominada por procesos autocíclicos, que fue continua en el tiempo y homogénea en toda la cuenca. A continuación, durante una fase sinorogénica temprana, la sedimentación estuvo controlada por eventos catastróficos, fundamentalmente volcánicos, originados en una cuenca fragmentada y con un paisaje recién formado. La fase sinorogénica ulterior se caracterizó por el depósito de una potente secuencia turbidítica típicamente flyschoide.

El relleno de la cuenca devónico-carbonífera de la FPI está formado por un armazón de pizarras con cantidades variables de materia orgánica, entre las que se intercalan rocas de diferente naturaleza que permiten diferenciar tres grandes unidades litoestratigráficas (Schermerhorn, 1971 Pág. 266-268). De muro a techo son: Grupo de Pizarras y Cuarcitas (PQ), Complejo Vulcano sedimentario (CVS) y Grupo Culm.

La Faja Pirítica Ibérica (FPI) es uno de los distritos minero más importante de España y del mundo. La FPI se extiende desde Sevilla hasta el océano Atlántico al 
sur de Lisboa en Portugal y está constituida por rocas volcánicas y sedimentarias de edad Devónico-Carbonífero que contienen importantes depósitos de sulfuros masivos poli-metálicos. La secuencia estratigráfica general incluye, de base a techo, una unidad de sedimentos pre-volcánicos (grupo PQ, Devónico), un complejo volcano-sedimentario (VS) constituido por rocas volcánicas máficas y félsicas, en alternancia con pizarras y areniscas volcano-derivadas, y una secuencia sedimentaria post-volcánica (facies Culm, Carbonífero Inferior).

La FPI (FPI) se caracteriza por su gran productividad metalogénica, hasta el punto de ser considerada la provincia de sulfuros masivos con mayores reservas del mundo. Incluye más de 80 depósitos, algunos de ellos supergigantes (>100 Mt) (Sáez et al., 1997, Pág 565-570; Sáez et al., 1999, Pág. 7-10; Leistel et al., 1.994, Pág. 236; Barriga et al., 1997, Pág. 15-20), entre ellos, destaca Riotinto, que es considerado el mayor depósito del mundo en su clase ( $>500 \mathrm{Mt})$. Las reservas originales totales se estiman en más de mil setecientos millones de toneladas, de las que se estima que se han explotado el $20 \%$ y que se han erosionado del orden del 1,5\% (Barriga et al., 1997, Pág 12).

La extracción de recursos minerales, en la FPI, se remonta al comienzo del uso de los metales, hace unos 5000 años (Pérez, J.A., 1996, Pág. 52-56). Desde entonces, han alternado épocas de intensa explotación con otras de escasa o nula actividad. El interés económico se ha centrado a lo largo de los años en la producción de $\mathrm{Cu}, \mathrm{Zn}, \mathrm{Pb}$, ácido sulfúrico, Ag y Au, estos dos últimos a partir exclusivamente de mineralizaciones oxidadas.

Figura 4. Esquema geológico de la FPI

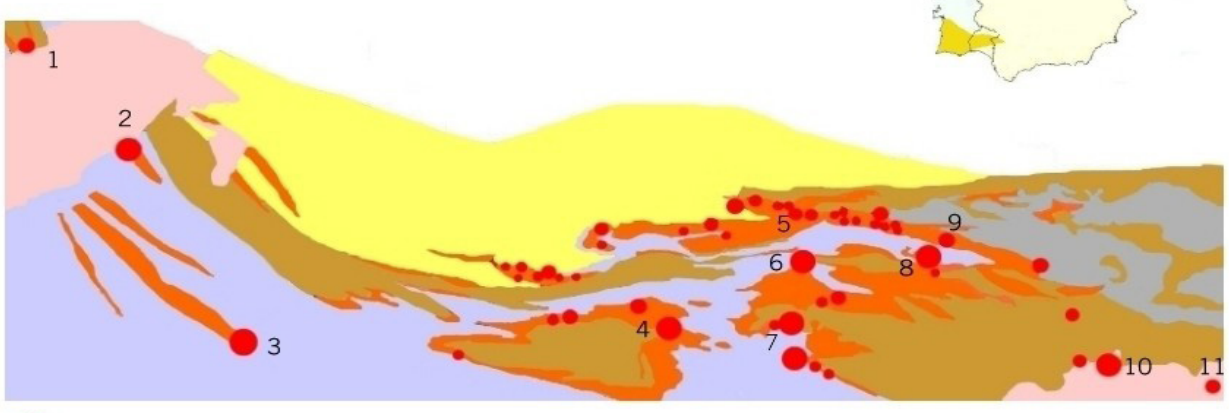

Explotaciones: 1.Lousal; 2.Aljustrel; 3.Neves Corvo; 4.Tharsis; 5.Aguas Teñidas; 6. La Zarza; 7. Sotiel; 8. Riotinto; 9. Peña de Hierro; 10. Aznalcollar; 11. Las Cruces.

UNIDADES DE LA ZONA SUBPORTUGUESA (de techo a muro): GRUPO CULM COMPLEJO VULCANO SEDIMENTARIO C GROPO P-Q

Fuente: Gemio, G., et al, 2006, Pág. 38-39. 


\section{Síntesis Histórica}

La riqueza en minerales de la Cuenca Minera de Riotinto ha determinado que desde épocas pretéritas el haya sido intensamente explotada. Las labores mineras más antiguas han sido documentadas en la mina de Cuchillares (Campofrío) datadas en el III mileno antes de la era cristiana, durante el calcolítico o edad de cobre (Blanco y Rothemberg. 1981, Pág. 165) cuando se desarrolló una minería basada en la explotación de carbonatos de cobre (malaquitas y azuritas) el agotamiento de este tipo de yacimiento durante el bronce inicial y medio llevó al comienzo de la explotación de la zona de enriquecimiento secundario donde se encuentran los minerales ricos en plata, el yacimiento donde se ha documentado la metalurgia argentífera más antiguo de Europa occidental es en la Parrita (Nerva) con una cronología de 2900 a. C.(Pérez, 1996, Pág. 52-56).

La famosa plata de Tarteso, atraerá a pueblos orientales (fenicios y griegos) a las costas onubenses y con el aumento de la demanda vendrá el aumento de la producción que se regulará a fines del siglo VI a. C. cuando Pisístrato abra las minas de plata de Laurion y no haga falta cruzar el estrecho de Gibraltar dando lugar al sombrío periodo turdetano de los siglos V y IV a. C. (Pérez, 1996, Pág. 52-56) Hispania y sus minas entrarán en el área de influencia de Cartago con el fin de la primera Guerra Púnica y durante la segunda pasarán a formar parte del Roma, concretamente a partir del año 206 a. C, así durante siete siglos, hasta el año 418 d. C., se desarrollará el primer gran período la Cuenca Minera de Riotinto como demuestran los 16 millones de toneladas de escoria romana, siendo la mina de plata más Importante del Imperio Romano (Pérez y Delgado 2011, Pág. 34-37).

En época medieval y moderna siguió explotándose los criaderos minerales Riotinto, pero la importancia de la explotación del período romano y la que devendrá en la segunda mitad del siglo XX ensombrecerán esos siglos. Desde principios del s. XVIII la necesidad de metales, principalmente cobre para acuñación de monedas y artillería para la marina llevará buscar las minas que tenían explotaciones antiguas, sobre todo romanas para ser reaprovechadas. Así durante 148 años Riotinto fue trabajada de forma directa desde la Real Hacienda o arrendándola a particulares en algunos períodos, pero la falta de inversión estatal llevo a una infraexplotación del yacimiento. Aunque será en la segunda mitad del siglo XIX cuando se comenzarán a explotar todas las concesiones mineras, debido a la demanda de azufre de la naciente industria química, extraído de la pirita, tras el agotamiento del azufre de Sicilia y la necesidad de imperiosa de cobre hará de polo de atracción para la venida de capital extranjero, a lo que se sumó la necesidad de liquidez de la I República española, así en 1873 las minas de Río-Tinto fueron vendidas a un consorcio de capital extranjero, Río Tinto Company Limited por noventa millones de pesetas. 
Está compañía invirtió en Riotinto aplicando las mejores tecnología para la extracción y metalurgia, cambiaron el sistema de minería de interior a cielo abierto; introdujeron el ferrocarril como sistema de transportes; nuevos sistemas de organización del trabajo e incluso trajeron su forma de pasar los ratos de ocio, lo que explica que Riotinto sea la cuna de todos los deportes británicos en España: Futbol; polo, cricket, tenis, etc. (Regalado et al, 2011, Pág. 50-55).

Todos estos cambios hicieron de Riotinto una de las minas de cobre más importantes del mundo desde el último tercio del siglo XIX hasta los años 30 del siglo XX (Harvey, C.E, 1981, Pág. 314-322), cuando primero la guerra civil española y luego la posguerra con el afán del gobierno del general Franco por hacerse con el "Gibraltar económico”, haga que Río Tinto Co. Ltd. invierta lo mínimo posible, así se llegó a 1954 cuando se van a juntar los intereses de un gobierno que quiere comprar y la empresa minera que quiere vender, así se constituyó un consorcio constituido por todos los bancos de España, menos el Santander, que con el Banco de España a la cabeza compraron el 66\% de Riotinto por 1000 millones de pesetas, constituyéndose la Compañía Española de Minas de Rio Tinto. A fines de los años sesenta la fundición y la fábrica de ácido fueron trasladadas a Huelva para formar parte del Polo Químico además se comenzó el proyecto Cerro Colorado para la extracción de oro y plata del mineral de gossan mediante el proceso Merryl - Crowe, con lo que se pasó de una mina de cobre a una mina de oro y plata. A principios de los años 80 la bajada de los precios del cobre determinó el comienzo de la crisis de la minería, así en 1986 se cerró la línea de cobre y sólo se continuó con la explotación de gossan para oro y plata. El 1 de agosto de 1995 la mina fue vendida a los trabajadores, separadamente de la Fundición de Cobre por primera vez desde 1725 y se constituyó Minas de Río Tinto Sociedad Anónima Laboral que explotó Riotinto hasta que los bajos precios del cobre hicieron insostenible económicamente el laboreo minero así la producción cesó el 9 de septiembre de 2001. El alza de los precios del cobre actual que supera los 8000 dólares tonelada hace que haya un proyecto de reapertura.

\section{El Parque Minero de Riotinto}

Los puntos de visita que conforman el Parque Minero de Riotinto y los trabajos de rehabilitación desarrollados en cada uno de ellos se describen en este epígrafe. Pero sin dejar atrás un aspecto que creemos importante destacar. Cuando hemos definido Fundación Río Tinto, nos hemos referido a esta institución como docente. Pues desde su creación se ha acogido a programas formativos que han ayudado a los jóvenes de la comarca, que no habían terminado la formación reglada a retomar su itinerario pero aprendiendo un oficio. Esta labor ha dado como resultado la formación de más de 700 alumnos-trabajadores en profesiones diversas, consiguiendo un grado de profesionalización elevado y unos porcentajes de inserción laboral importantes cercanos al $70 \%$, a la vez que se han creado nuevos empleos a través de la realización de los objetos de actuación y sus usos 
posteriores, potenciando la figura del Parque Minero de Riotinto como un atractivo turístico más de la provincia onubense (Cabello, 2011, Pág. 616). Siendo los hijos y los nietos de mineros quienes han rehabilitado este patrimonio, lo cual aporta al proyecto un importante valor social.

Los puntos integrantes del Parque Minero son: a) Museo Minero de Riotinto, b) Casa n ${ }^{\circ} 21$ de Bella Vista, c) Ferrocarril Turístico Minero y d) Mina Peña de Hierro

a) Museo Minero de Riotinto (tomado de Delgado y Regalado, 2011a, Pág. 491-518)

La actual sede del Museo Minero es el edificio que albergó el hospital de Río Tinto Company Limited, está situado en la colina sur de El Valle (Minas de Riotinto (Huelva). El edificio fue proyectado por el arquitecto británico R.H. Morgan en 1925. Consiste en un edificio de cuatro cuerpos paralelos unidos por una pasillo central que los cruza por su parte central con cubierta a dos y cuatros aguas mediante teja plana de tipo inglés. El hospital fue terminado en 1927 con un coste de $23.720 £$ (779,743, 70 pesetas de la época). Siendo su función la atención sanitaria de los empleados de Río Tinto Company Limited, tanto personal británico como español e incluso aquellas personas residentes en la zona sin relación con la compañía británica que no podían costearse su propia sanidad las llamadas "camas de gracia”.

En 1983 este edificio perdió su funcionalidad al ponerse en servicio el actual Hospital y se cerró hasta que en 1987 pasó a formar parte de los activos de Fundación Río Tinto.

El trabajo desarrollado en el antiguo Hospital de El Valle se puede agrupar en los siguientes tipos: rehabilitación del edificio, recuperación de la arquitectura original, adaptación del edificio a Museo y la evolución museográfica y de las condiciones de confort y conservación de las piezas que en él se custodian. 
Figura 5. Museo Minero

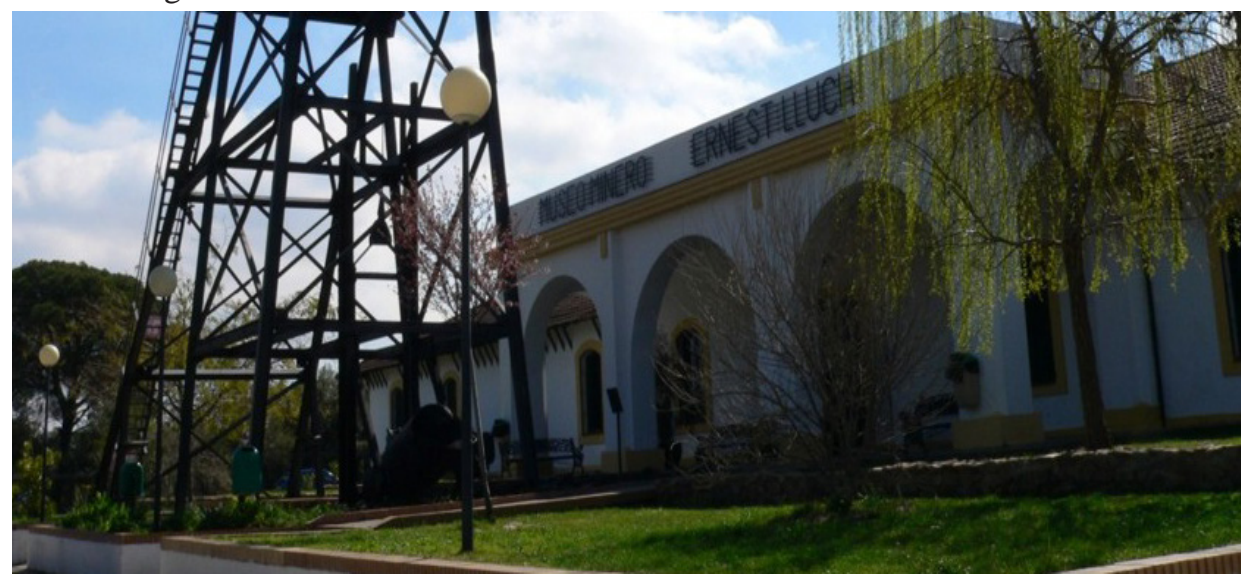

La primera fase es a la apertura del Museo y el trabajo se circunscribió a la rehabilitación del pabellón Sur y de parte del pasillo central, una vez realizado el montaje museográfico se abrió al público la mitad (actuales salas $\mathrm{n}^{\circ} 3,4,5,6$, y 7) el 14 de abril de 1992, en noviembre del mismo año se abriría la segunda mitad del pabellón (actuales salas $\mathrm{n}^{\circ} 8,9,10,11$ y12). Entre 1992 y finales de 1995 se desarrolló la segunda fase. La zona de actuación fue principalmente el pasillo y el pabellón central (actuales salas $\mathrm{n}^{\circ} 1,2,13,14,15$ y 16). Los trabajos realizados permitieron la instalación de la sala polivalentes para usos audiovisuales (actual sala $\mathrm{n}^{\circ} 13$ ). En el ala derecha del pabellón central se dispuso la zona de descanso y tienda del Museo (actuales salas $\mathrm{n}^{\circ} 1$ y 2 ), mientras que en el ala izquierda (actual sala 14) se reprodujo un andén ferroviario, donde se introdujeron tres piezas provenientes del Ferrocarril Minero de Río Tinto (actual sala 14). Flanqueando esta sala se dispusieron dos salas de exposición temporal (actuales salas 15 y 16).

La tercera fase daría comienzo en 1998 desarrollándose en el pabellón norte, donde se habilitó el lado derecho como zona de gestión, biblioteca y fondos, mientras que la izquierda se destinó para la zona de tienda, cafetería, recepción y servicios, recuperándose como espacio expositivo el ala derecha del pabellón central (actuales salas $\mathrm{n}^{\circ} 1$ y 2 ). Durante esta fase también se recuperó la arcada que originalmente estaba situada en el acceso principal y el malacate de masa Planes.

En este sentido la principal intervención fue la construcción de la reproducción de mina romana entre 2000 y 2001, para ello se adaptó la antigua zona destinada a la zona de gestión de fondos, aprovechándose la antigua sala de calderas y el sótano. Durante el año 2002 y 2003 se procedió a la reforma de la sala n 12 y a su nuevo montaje expositivo. 
El año siguiente se renovó el montaje expositivo de la sala $\mathrm{n}^{\circ} 5$ y 6 , dedicadas al período romano. Desde el año 2004 se ha trabajado interrumpidamente en el aislamiento de la cubierta del Museo, completado en 2008 con la climatización. Desde este año el objeto de actuación ha sido la mejora y modernización del discurso museográfico, en el cambio de iluminación a LED y la climatización.

El Museo Minero de Riotinto está integrado en la Red de Museos de la Comunidad Andaluza (Orden de 14 de Marzo de 1997. B.O.J.A. no 50 de Abril de 1997) y declarado Bien de Interés Cultural, con la categoría de Zona Patrimonial (B.O.J.A. 222 de 11 de noviembre de 2011). Conserva, custodia y expone la cultura material generada por 5.000 años de minería y metalurgia. Este museo está conceptuado como ecomuseo, pues su función excede de los muros de la institución pues su principal cometido es explicar al visitante la Cuenca Minera de Riotinto.

Dispone de una superficie total de $2340 \mathrm{~m}^{2}$. Distribuida entre espacio de uso público y privado. Dentro del espacio de uso público cuenta una zona de asueto de 320 metros cuadrados ocupados por la tienda y la cafetería. Ubicadas en el ala izquierda del primer cuerpo del edificio. En esta misma área se encuentran también la recepción y los aseos. La parte dedicada al solaz de los visitantes se complementa con el jardín situado en la entrada del Museo. La superficie dedicada a la zona de exposición permanente del Museo Minero es de $1690 \mathrm{~m}^{2}$, donde se exhibe la colección permanente que está distribuida en tres espacios expositivos:

- Espacio Expositivo n 1 Geología (Sala1): Mediante cartelería y un conjunto de minerales de la faja pirítica se muestra la génesis geológica de la Cuenca Minera de Riotinto y las diferentes mineralizaciones.

- Espacio Expositivo $n^{\circ} 2$ Arqueología Clásica y medieval (Salas n ${ }^{\circ} 3, n^{\circ} 4, n^{\circ} 5, n^{\circ} 6, n^{\circ}$ 7 y nº13): En estas salas se muestran las época más pretéritas de la explotación minera y metalúrgica desde el Calcolítico o edad del cobre, pasando por la época tartésica hasta época medieval, destacando el primer gran período de explotación época romana, cuando Riotinto fue la mina de plata más importante del Imperio romano. Este espacio está completado con la Reproducción de la Mina Romana un recorrido de 250 metros, donde se han recreado todos los elementos típicos de la minería romana, destacando los sistemas de desagüe como la pareja de norias y el tornillo de Arquímedes en la antigua cocina y zona de calderas. 
Figura 6 Norias, Reproducción de Mina Romana.

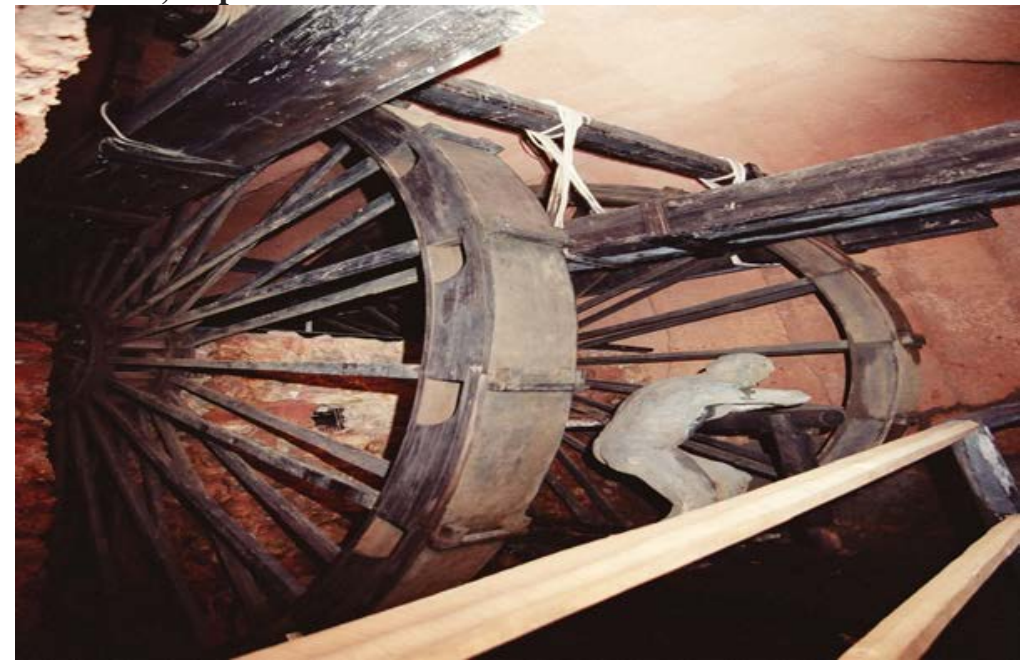

Figura 7 Vagón del Maharajá

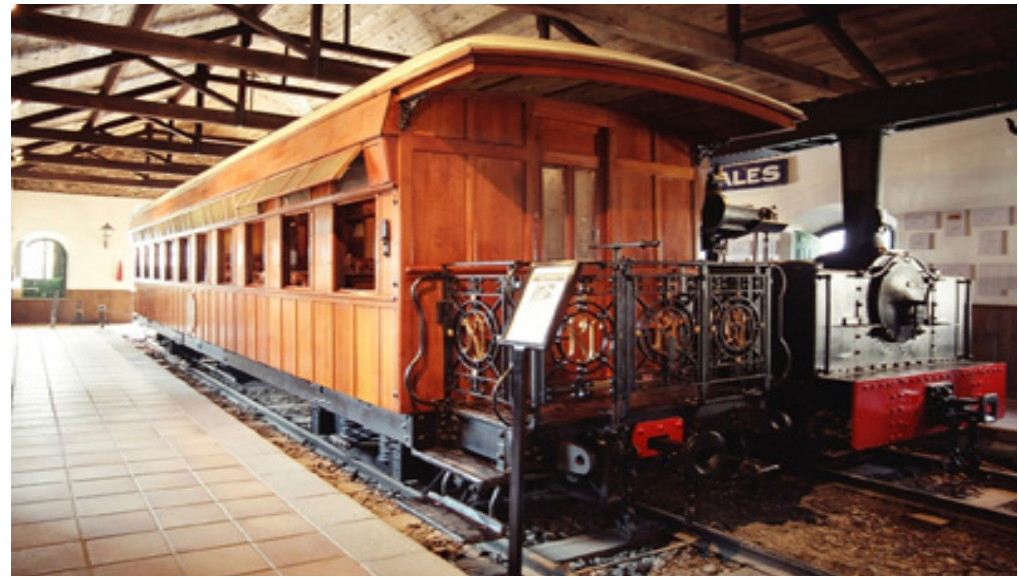

- Espacio Expositivo $n^{0}$ 3: Arqueología industrial (Salas $n^{\circ} 8, n^{\circ} 9, n^{\circ} 10, n^{\circ} 11, n^{0} 12$, $\mathrm{y} \mathrm{n}^{\mathrm{o}}$ 14). Colección de artefactos generados por la explotación de las minas desde 1725 pasando por las diversas compañías mineras desde la llegada de la Río Tinto Co. Ltd en 1873, el segundo gran período de explotación, hasta el cierre de la actividad minera en 2001. Dentro de este espacio destaca la sala n ${ }^{\circ} 14$ "Ferrocarril Minero de Riotinto" dedicados a mostrar una de las líneas ferroviarias más importantes del país. Para tal fin 
se ha recreado un andén ferroviario y se ha expuesto tres piezas representativas del Río Tinto Railway: el Coche de viajeros de primera clase del tipo "B” conocido como Vagón del Maharajá, el más lujoso del mundo en vía estrecha (Delgado y Regalado, 2006, Pág. 234); locomotora de vapor tipo $\mathrm{K}, \mathrm{n}^{\circ} 106$ y la locomotora grúa de vapor tipo $\mathrm{N} \mathrm{n}{ }^{\circ} 150$.

Además del área de exposición permanente este Museo cuenta con una zona dedicada a las exposiciones temporales situadas en las salas $\mathrm{n}^{\circ} 15 \mathrm{y} \mathrm{n}^{0} 16$. También dispone de una sala audiovisual para usos múltiple situada al inicio del pasillo central justo en la entrada. La zona de uso privado tiene una superficie de 320 metros $^{2}$, en el ala derecha del primero de los tres cuerpos que componen el edificio. Dentro de ésta se incluyen las dependencias de Administración y Gestión; el laboratorio de restauración; la biblioteca especializada sobre Minería y Metalurgia, con más de 900 volúmenes y los fondos con una superficie de $120 \mathrm{~m}^{2}$.

\section{b) Casa $n^{\circ} 21$ de Bella Vista (tomado de Delgado y Regalado, 2011b, Pág. 519-526)}

La Casa $n^{0} 21$ del Barrio de Bella Vista (Minas de Riotinto, Huelva) es la Sección Etnográfica del Museo Minero. Fue inaugurada el 28 de julio de 2005. Está integrada junto con el Museo Minero en la Red de Museos de la Comunidad Andaluza (Orden de 14 de Marzo de 1997. B.O.J.A. no 50 de Abril de 1997) y está declarada Bien de Interés Cultural, con la categoría, con la categoría de Zona Patrimonial (B.O.J.A. 222 de 11 de noviembre de 2011).

En 1873 un consorcio financiero extranjero con mayoría de capital británico compró las minas de Riotinto, constituyendo la empresa Rio Tinto Co. Ltd. Iniciándose así la presencia británica en la Cuenca Minera de Río Tinto que perdurará hasta 1954. Desde el primer momento la dirección técnica de las labores mineras será llevada a cabo por técnicos extranjeros, principalmente británicos. En un principio se alojaron en el antiguo pueblo de Riotinto, pero por un lado, el hecho de que la actividad minera en Filón Sur iba a fagocitar el pueblo y por otro la proximidad a los trabajadores, lo cual equivalía a estar en la primera línea de las distintos movimientos obreros. Todo lo cual provocó que en 1882 Charles Prebble General Manager decidiera con la aprobación de la compañía minera, la construcción de un barrio donde albergar el "staff”. Para ello eligió una pequeña colina de escoriales antiguos al oeste del pueblo, conocido como "Bella Vista" debido a que desde ella dominaban una serie de pequeños valles y planicies en dirección N.O. 
Figura 8 Fachada Casa no 21.

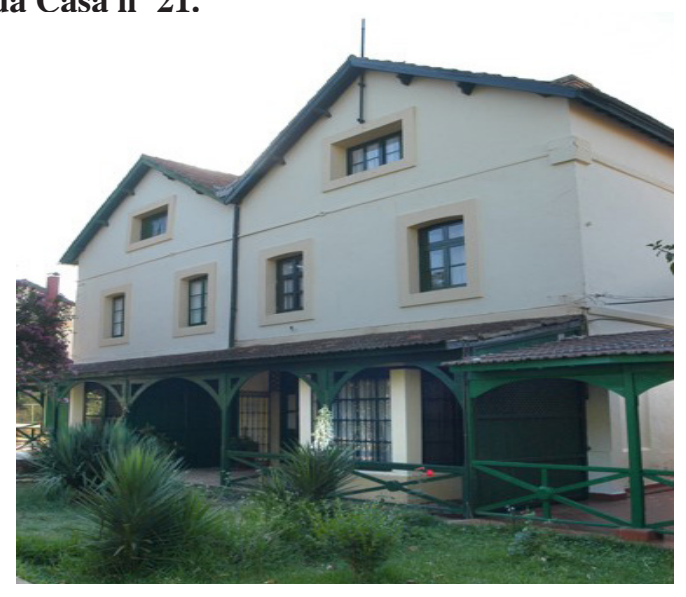

Figura 9 Salón Casa $n^{0} 21$

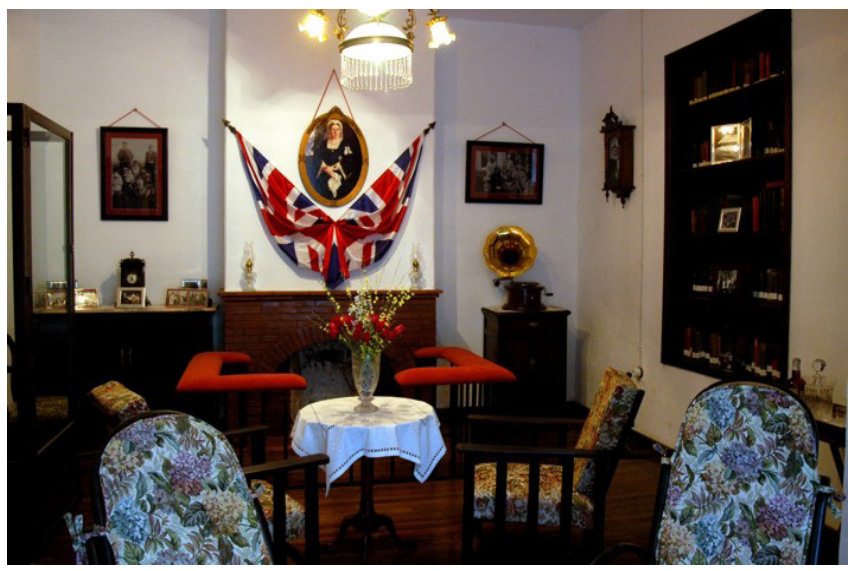

Las primeras casas pareadas, entre las que se encontraba la casa $\mathrm{n}^{0} 21$ originalmente numerada como $\mathrm{n}^{\circ} 10$, fueron construidas en 1883. La estructura de la vivienda es de forjados y cubiertas de madera sobre muros de carga. Los muros, de 45 centímetros de espesor están hechos de mampostería y de ladrillo y posteriormente enfoscados. De muro a muro existen siete vigas de madera en las habitaciones, en sentido frontal a la calle, que soportan el entarimado del suelo. En la escalera, también de madera, se resuelve el forjado con una viga de madera ensamblada a otras dos. La cubierta es a dos aguas en el cuerpo de cocina y lavadero, de teja plana sobre pares de madera. En el resto de la casa y cubriendo el doblado, existe un tejado a dos aguas a la calle y a patio, del que emergen las ventanas abuhardilladas con cubiertas contrarias y hastíales a fachada. Se cubre con pares apoyados en cumbreras y vigas intermedias de ayuda perpendiculares 
a los muros de carga transversales, que adoptan forma de piñón. Las casas se disponen pareadas usando los muros medianeros como muros de carga comunes semi-detached house.

Fundación Río Tinto adquirió la Casa n 21 en 1996 y desde entonces ha venido trabajando en ella. La labor realizada se ha desarrollado en tres fases. Primero se procedió a la recuperación de la arquitectura victoriana original, siguiendo los planos conservados en la Cartoteca del Archivo Histórico de Fundación Río Tinto. Todos los trabajos de esta fueron realizados mediante programas formativos de Escuelas Taller y Talleres de Empleo. Segundo se dotó la Casa 21 con mobiliario de época. En este punto se hace necesario reseñar que un $20 \%$ de lo expuesto es fruto de donaciones realizadas desinteresadamente. Tercero y último se llevó a cabo el montaje museográfico de la misma, realizado por el Departamento de Conservación de Fundación Río Tinto.

La Casa $\mathrm{n}^{\circ} 21$ posee tres plantas y dos jardines con una superficie total de 540 $\mathrm{m}^{2}$. En la planta baja se sitúa la zona donde se realizaba la vida diaria (comedor, salón, vestíbulo, jardín delantero y trasero etc.). Además de las zonas de servicio (cocina, lavadero, leñera, w.c. del servicio, etc.). En la primera planta se ubican los dormitorios, el estudio y el w.c. En la segunda planta se ubican las habitaciones del servicio doméstico, el trastero y el cuarto de juegos. Además de restaurar todas las dependencias de la casa se han dispuesto dos espacios expositivos. El primero situado en el estudio está dedicado a exponer las razones que llevaron a la dirección de Río Tinto Co. Ltd a construir el Barrio de Bella Vista, las distintas fases en que fue edificado y los edificios que lo componen (viviendas, capilla y club inglés). El segundo ubicado en el antiguo cuarto de juegos está dedicado a mostrar con fotografías históricas y cartelería como se desarrolló la vida cotidiana de la colonia británica durante casi un siglo. Por último se ha instalado un sistema de audio que permite la visita libre. Así acercarse a conocer esta sección del Museo Minero es realizar un viaje en el tiempo a la época victoriana.

\section{c) Ferrocarril Turístico Minero}

Para transportar el mineral y el producto de la fundición desde la zona de extracción y procesado en Riotinto a Huelva Río Tinto Co. Ltd. inició en 1873 la construcción de una línea férrea. Este sistema ferroviario, construido en el tiempo record de 25 meses, fue planeado y supervisado por George Barclays Bruce, quien diseñó un ferrocarril de vía estrecha (1,0668 mts) de 83,524 kilómetros, correspondientes a la vía "vía general” o "main line" que unía la zona minera con Huelva. Además se construyeron 264 kms de carril destinado a ramales que servían para unir los distintos tajos (talleres, almacenes, filones, etc.) con las poblaciones mineros. (Delgado, 2009, Pág. 19-23).

El importante tráfico del Ferrocarril Minero de Río Tinto determinó la existencia de un numeroso parque móvil. Llegó a contar con 147 locomotoras de vapor, nueve 
locomotoras Diesel Hidráulicas, seis automotores de tipos diversos, 21 locomotoras eléctricas de varias clases y una locomotora de aire comprimido. En cuanto al material remolcado contó con 1.300 vagones de distintos tipos y 2.000 vagonetas de mina. Además de 36 coches para el servicio de viajeros. (Delgado, 2009, Pág. 24)

La pérdida de funcionalidad del ferrocarril sobrevino a partir de 1964 cuando se construye el Polo Químico de Huelva. Desde entonces, y dado que el mineral ya no se embarcaba hacia Inglaterra, resultó más rentable transportarlo en camiones. Así, en 1975 el muelle de Río Tinto dejó de funcionar y el ferrocarril transportaba el mineral desde la zona de extracción sólo a la estación de las Mallas (Niebla, Huelva). Hasta febrero de 1984 cuando se cerró la línea terminando así 109 años de historia del Río Tinto Railway, período en el cual se estima que llegó a transportar 130 millones de toneladas métricas de mineral. (Delgado, 2009, Pág. 25).

En 1987 la compañía Río Tinto Minera S.A., cuando crea Fundación Río Tinto, entre sus objetivos estaba la restauración y rehabilitación del Patrimonio Ferroviario (Delgado, 2009, Pág. 54). El trabajo desarrollado desde los inicios hasta la actualidad se puede dividir en dos grandes apartados, Parque Móvil e Infraestructuras Ferroviarias.

Poner en marcha una línea férrea hizo necesario rehabilitar el parque móvil con que fue dotada Fundación Río Tinto. Habiéndose puesto en orden de marcha dos locomotoras de vapor, las más antiguas de España en orden de marcha. La $\mathrm{n}^{\circ} 14$ de la clase "C", construida en 1875 por Beyer \& Peacock Co. Ltd. y la n 51 de la clase "I", construida en 1883 por Dübs. Se restauraron dos locomotoras para ser expuestas en el Museo Minero, la $\mathrm{n}^{\circ} 106$ de la clase "K", construida en 1907 por North British Locomotive and Co. Ltd. y la $\mathrm{n}^{\circ} 150$ tipo de la clase "N" construida en 1930 por Hawthorn Leslie and Co., locomotora-grúa única en sus características en España. Ambas ubicadas en la sala $n^{\circ} 14$, del Museo Minero. Actualmente se está trabajando en la reparación de la nº 146 “Garratt” construida en 1929 Beyer \& Peacock Co. Ltd., la de mayor tamaño del Ferrocarril de Río Tinto y la no 204 tipo “200”. (Delgado, 2009, Pág. 61-84) 
Figura 10. Locomotora ${ }^{\circ} 14$;

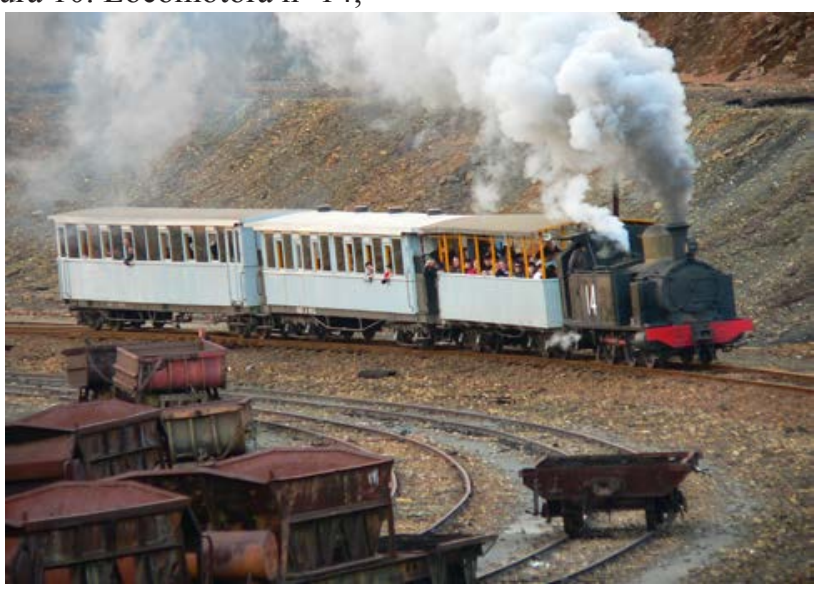

Figura 11 Locomotora Diesel 932.

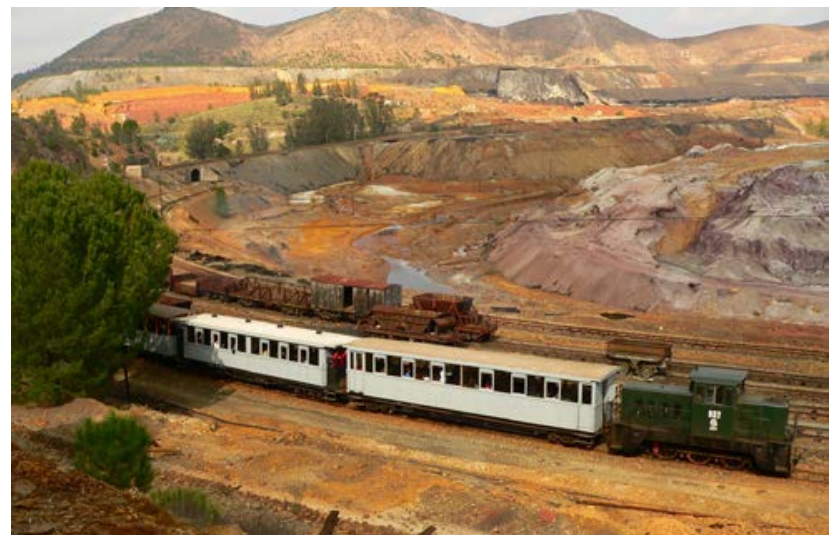

Las intervenciones sobre el Parque Móvil Diesel se han puesto en orden de marcha tres locomotoras. La n 933 de la clase "300”, fabricada en 1960 por Fried-Krupp. La primera locomotora diesel del Ferrocarril de Río Tinto. Las número $\mathrm{N}^{\circ} 931$ y $\mathrm{N}^{\circ}$ 932 de la clase "500", fabricada en 1975 por S.E.C. BABCOCK \& WILCOX (Bilbao). Licencia HUNSLET y por último el automotor n ${ }^{\circ} 941$ "Dresina” Autovía para el servicio de jefes, construido en 1961 por Talleres Huelva. De ellas las tres primeras son empleadas en el servicio de viajeros y la última para servicios auxiliares. Estando en reparación el Automotor Billard $n^{\circ} 942$ construido en 1967 por Sociedad Minera y Metalúrgica de Peñarroya. Licencia E. Billard. (Delgado, 2009, Pág. 84-100) 
En cuanto al Parque Móvil Eléctrico se rehabilitó la locomotora nº 1 de la clase "P” construida en 1916 por General Electric, fue la primera de tracción eléctrica adquirida por RTCL, actualmente se halla expuesta en la sala $\mathrm{n}^{\circ} 12$ del Museo Minero. (Delgado, 2009, Pág. 101-106)

Pero poner en marcha el Ferrocarril Turístico Minero hizo necesario restaurar unidades del Parque Móvil Remolcado, habiéndose restaurado dieciséis. De ellas cuatro vagones de pasajeros de tercera clase tipo "J" cubiertos y dos vagones jardineras para el servicio de viajeros. Para el servicio auxiliar en la vía se tienen en orden de marcha un vagón aljibe; un vagón tolva tipo "A" de 10 tn; un vagón tolva tipo "M" de 30 tn; 2 vagones de mercancías tipo "A", empleados como vagones de auxilio y 2 bateas de balasto. Además se reparó para ser empleada una grúa de sangre de 15 toneladas construida en 1905 y para exposición en Zarandas una de vapor de 4 toneladas. (Delgado, 2009, Pág. 107-160)

A la misma vez se comenzó la restauración de las infraestructuras ferroviarias, que podemos agrupar en tres grandes apartados: Tendido férreo, elementos de señalización, información y cambio y por último Estaciones y apeaderos.

La primera intervención fue recuperar el tendido férreo, primero entre el tramo Talleres Mina a Zarandas, y posteriormente entre Zarandas y Los Frailes, estando actualmente en servicio 12 kilómetros (Delgado, 2009, Pág. 162-182). La necesidad de una circulación en condiciones de seguridad llevó a que se repararan, repusieran y reprodujeran todos los elementos de cambio y cruzamiento e información dañados por el paso del tiempo y los expoliadores, además rehabilitó la Casa de Palancas Norte y la de la Estación de los Frailes. Se construyó en el Centro de Recepción de Visitantes de Talleres Mina una plataforma giratoria para el cambio de sentido. Se ha repuesto todo el sistema de señalización del tramo en cuestión incluyendo la réplica de un sistema de pórtico de señales de diseño Stevens en la Estación de los Frailes. Tanto en Talleres Mina como en Zarandas se ha construido depósitos de agua para el servicio de las locomotoras de vapor. En la última de las dos también se dispuso una carbonera y un depósito de gasoil para el servicio Diesel. (Delgado, 2009, Pág. 183-194).

Por último se hizo necesario rehabilitar las Estaciones y Apeaderos para regular el tráfico de viajeros (Delgado, 2009, Pág. 161-179). Para comenzar la recuperación del tendido ferroviario en las cercanías de los antiguos Talleres Mina, se construyó una pequeña estación ferroviaria, donde acoger a los visitantes, estando adaptado para minusválidos. En la zona anexa se construyó un aparcamiento para turismos y otro para autocares. La estación de Zarandas fue el siguiente objeto de actuación. Por último la estación de Los Frailes es la última que ha sido restaurada. Además de estas estaciones también se reparó y rehabilitó la estación de Nerva, que una vez finalizados los trabajos 
no se puso en servicio en el Ferrocarril Turístico Minero, pues el trazado viario original es incompatible con la actual red de carreteras, sino que se adaptó como Albergue Juvenil hasta la actualidad.

Toda esta labor de restauración del patrimonio ferroviario permitió poner en servicio el 4 de noviembre de 1994 el Ferrocarril Turístico Minero, en principio con tracción diesel, desde Talleres Mina a Zarandas y menos de tres años después llegar a la estación de los Frailes con tracción vapor, en concreto el 13 de febrero del 1997. Desde entonces el visitantes puede disfrutar de un increíble viaje en antiguos vagones y locomotoras restauradas de tracción diesel y vapor sobre ésta antigua línea comercial, paisajes mineros, parajes naturales siempre acompañando el curso del río Tinto, un río que da nombre a este singular territorio.

d) Mina Peña de Hierro (Delgado y Regalado, 2009, Pág. 55-63)

Peña de Hierro se encuentra en el extremo norte-oriental del anticlinal de Riotinto, a unos $10 \mathrm{Kms}$. de la población de Minas de Riotinto y a unos $3 \mathrm{Kms}$. de la de Nerva. Se trata de una mina menor comparadas con las de Riotinto pero con unas leyes en metales bastante altas. Debe su nombre al gran crestón ferruginoso que corona la mina a cielo abierto.

Peña de Hierro al igual que todas las minas del entorno está situada en una región geológica llamada la Faja Pirítica Ibérica, materiales con una edad de 165 millones de años y con un origen volcánico y sedimentario. Por esta razón estas tierras poseen gran cantidad de metales y sulfuros, materiales que han sido la base de la producción de toda esta comarca.

Los sulfuros masivos extraídos en Peña de Hierro mediante sistema de voladuras y cámaras subterráneas y posterior tratamiento físico y químico, sirvieron para la obtención sobre todo de cobre, azufre y otros polimetálicos. Estos productos eran introducidos en el mercado mediante transporte ferroviario destino en un principio Huelva y posteriormente Sevilla.

Aunque los primeros trabajos documentados pertenecen a época romana, el laboreo sistemático de Peña de Hierro comenzará en 1853 por parte de Agapito Artaloitia, a quien sucederán distintas compañías como Ntra. Señora de los Reyes (18531866), pasando a manos extranjeras en 1883 con The Peninsular Copper Company que explotará la mina hasta 1900. En 1901 comenzará el máximo período de explotación con la llegada de otra compañía minera de capital británico, The Peña Copper Mines, que será la que trabajará esta mina durante más tiempo, 54 años, que será quien más invertirá en infraestructuras para favorecer la rentabilidad de la producción hasta 1955 cuando pasará a manos españolas, concretamente a la Compañía Nacional de Piritas (CONASA) quien la mantendrá en producción hasta 1960, a partir de entonces sólo de desarrollaron labores de mantenimiento, siendo comprada en 1972 por Río Tinto Patiño, S.A., cesando 
toda actividad.

Figura 12 Corta de Peña de Hierro.

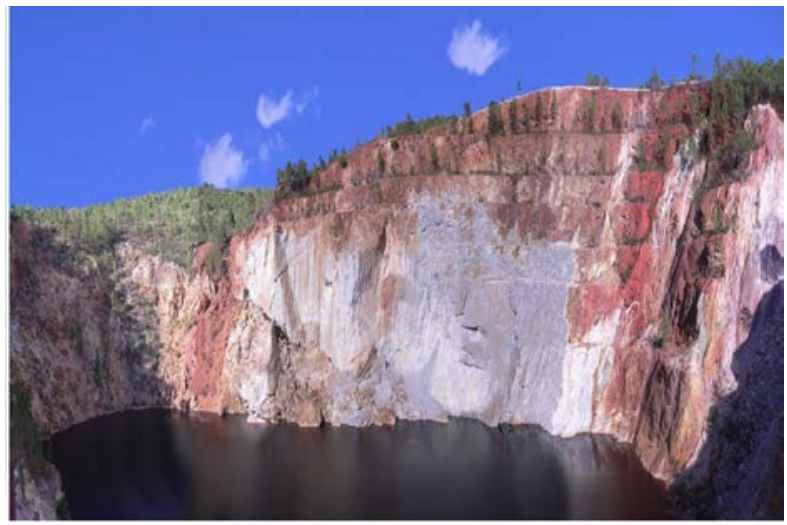

Desde su cierre definitivo esta mina abandonada sufrió el paso del tiempo y el de los expoliadores que han utilizado las antiguas instalaciones mineras como zona de aprovechamiento de materiales. Hasta que en 1987 pasó a formar partes de los activos de Fundación Río Tinto, que siguiendo con su política de restauración del patrimonio minero acometió la restauración de la mina de Peña de Hierro su posterior puesta en servicio turístico. (Delgado y Regalado 2009, Pág. 60)

La primera fase de la rehabilitación de Peña de Hierro comenzó a partir de 1996 que se pueden aunar en dos. Por un lado la Adecuación y acondicionamiento del tramo carretera de 1,1 km que da acceso a Peña de Hierro desde la carretera Nerva-La Granada de Riotinto, por el puente de Valdeburgo hasta la instalación industrial que nos ocupa, por el trazado de la antigua plataforma del FC. de Peña de Hierro y por otro las labores de desescombro y limpieza: Tras cuarenta años de abandono el estado de conservación de las antiguas instalaciones industriales era muy deficiente, por lo que los primero años estuvieron destinados a la limpieza y desescombro de las mismas (salida del Túnel Sta. María, antiguos depósitos de pirita, antiguo concentrador, tolva y trituradora, etc.). Además fue necesario el encauzamiento tanto de las aguas pluviales como de las ácidas provenientes del interior de la Mina, para tal fin se rehabilitó el canal de desagüe que parte del túnel Sta. María y se encauzó el canal de desagüe proveniente de la Corta, situado bajo la trituradora.

La segunda fase estuvo destinada a la adecuación de Peña de Hierro para las futuras visitas. Así se construyó junto a los antiguos almacenes de piritas una zona de aparcamiento. Partiendo de este parking se construyó un recorrido que permite visitar a 
pie Peña de Hierro. A partir de esta fase se sustituyó el suministro eléctrico proveniente de generadores por la energía solar.

La tercera fase estuvo destinada a solventar los problemas de seguridad que planteaba Peña de Hierro en cumplimiento de la Ley y Reglamento de Minas como del Reglamento General de Normas Básicas de Seguridad Minera, para solventar tal fin se procedió por parte de la Delegación Provincial en Huelva de la Consejería de Innovación Ciencia y Empresa a llevar a cabo a construir un muro perimetral de la Corta, también se procedió a la adecuación de los accesos de la misma mediante senderos que permiten su contemplación desde todos los puntos. Además se dispusieron miradores en el recorrido perimetral de la corta donde visitante pueda descansar y contemplar de forma reposada la belleza de la Corta de Peña de Hierro. Además se aseguraron mediante vallados y miradores el nacimiento del río Tinto con su cartelería correspondiente para facilitar el conocimiento de este ecosistema único en el mundo. También se construyó un mirador y el acceso a la zona de canaleos, donde mediante la señalética se explica el proceso para la obtención de cobre por vía húmeda. Todos los trabajos fueron desarrollados por mineros que se encontraban en situación de desempleo tras el cierre de las explotaciones, lo cual supuso un importante beneficio social. Durante esta fase se elaboró e instaló señalización de interpretación en todo el recorrido que rodea la corta, relativo tanto a Peña de Hierro (geología, historia, etc.) como de la faja pirítica en general, también se instaló una maqueta de la mina en braille y macrotipos que facilita el conocimiento de la corta a invidentes.

La cuarta fase del proceso de rehabilitación de Peña de Hierro, en la que todavía nos encontramos, ha estado destinada a la restauración y rehabilitación de los distintos bienes patrimoniales y su posterior puesta en uso turístico. En este sentido la primera actuación tuvo como objetivo el túnel Santa María, antiguo túnel que correspondía al segundo nivel, que en un primer momento tuvo un uso propiamente minero para posteriormente ser el lugar por donde se extraía el mineral de la Corta de Peña de Hierro.

La rehabilitación de esta antigua labor minera se realizó con una doble finalidad, por un lado rehabilitarla, pues se encontraba en estado de casi ruina tras más de treinta años de abandono y por otro permitir una visita segura que permitiera conocer de primera mano un trabajo minero de interior. Esta intervención constó básicamente en destapar la boca del túnel, que estaba cegada por los escombros; limpiar y sanear el interior del túnel; entibar aquellas zonas que indicó la jefatura provincial de Minas y por último se construyó un mirador al final del túnel a nivel del agua de la Corta de Peña de Hierro. Todas estas intervenciones permitieron poner en servicio turístico el túnel Santa María el 24 de noviembre de 2004 (Delgado y Regalado, Pág. 2009, 60).

Tras el túnel Santa María el segundo objeto de actuación tuvo como objeto el grupo pilones. Éste era un conjunto de edificios que originalmente tuvieron uso como 
viviendas para posteriormente emplearse como talleres. Si bien en un primer momento se proyectó la rehabilitación del edificio, las pésimas condiciones conservación que los técnicos competentes optaran por reconstruirlo empleando los mismos materiales y acabados. El uso previsto para este edificio rehabilitado es el de Centro de Recepción de Visitantes de Peña de Hierro, estando actualmente en proceso del montaje museográfico y equipamiento.

Figura 13: Malacate y Casa de máquinas;

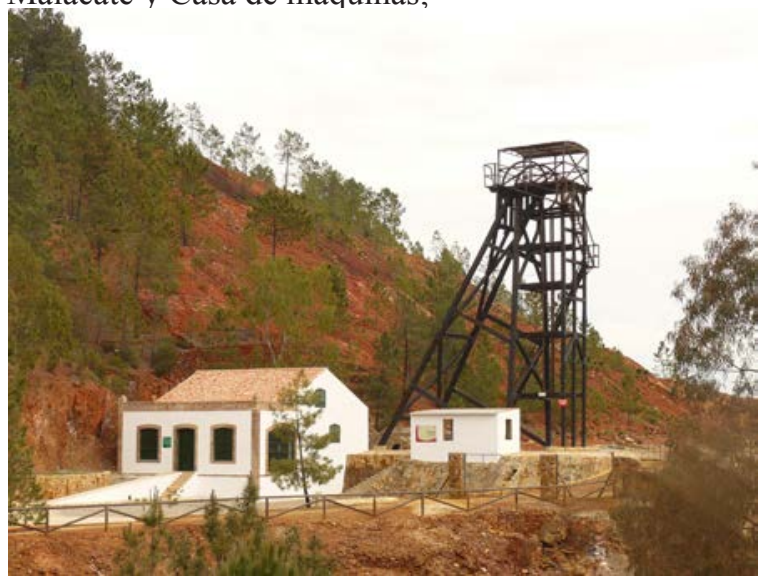

Figura 14: Túnel Sta. María.

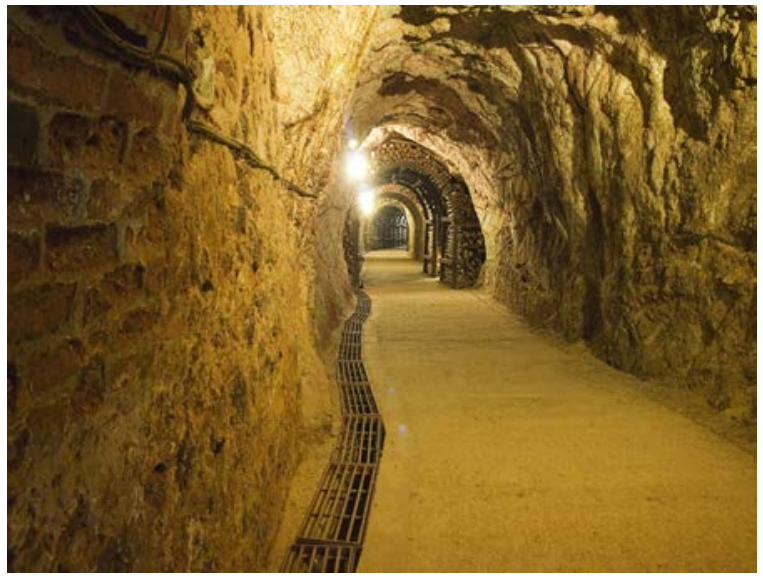

Conjuntamente con el grupo pilones se rehabilitó la esquina derecha de la tolva de la antigua planta trituradora construida en 1935 para procesar pirita tanto para la cementación como para venderla triturada. Esta esquina presentaba peligro por 
desprendimiento por lo que fue consolidada y reparada. La siguiente intervención de la cuarta fase estuvo dedicada a la rehabilitación de la Casa de Máquinas del Malacate o Castillete del pozo maestro de Peña de Hierro. Es el edificio que albergó el motor del malacate, en un primer momento de vapor y posteriormente eléctrico. Después de algo más de cuarenta años de abandono el edificio conservaba los muros en buen estado pero la cubierta y la carpintería habían desaparecido debido al paso del tiempo y al de los expoliadores. Así se procedió a la rehabilitación del edificio se reforzaron los paramento. Se repuso el sistema de cubierta original sostenido por cerchas metálicas y teja plana. También se repuso toda la carpintería en madera y en color verde carruaje, respetando las dimensiones de los vanos originales. La única aportación al edificio es la rampa dispuesta en la entrada para facilitar el acceso a discapacitados. Este edificio está previsto que sea la futura Sección Tecnológica del Museo Minero, donde se explique los dos sistemas empleados en minería desde mediados del s. XIX a inicios del siglo XXI en la Cuenca Minera: minería de interior o contramina y “a cielo abierto" o cortas, permitiendo explicar cuándo y porqué se emplea uno y otro sistema, las ventajas que presenta uno u otro sistema y por último el impacto medioambiental que implica el uso de un sistema u otro.

Durante 2006 y 2007, conjuntamente con la rehabilitación de la Casa de Máquinas del malacate, se procedió a la reproducción del malacate o castillete de las mismas características que el original: 18,85 m de altura por 12,29 $\mathrm{m}$ de base en su parte más ancha y 6,36 m en la más estrecha, y fabricado en madera. Esta acción permitió también recuperar el "skyline" original de Peña de Hierro además de musealizar y recontextualizar una zona de las instalaciones mineras, haciendo más comprensible las distintas labores mineras.

La actividad durante 2008 y 2009 ha estado destinada a rehabilitar una antigua casa de obreros del grupo San Carlos y su correspondiente urbanización. Siendo el fin de la misma, constituir en esta otra etnográfica del Museo Minero, para permitir conocer de primera mano cómo se desarrollaba la vida cotidiana de una familia minera española.

Desde 2011 se viene trabajando en colaboración de la Consejería de Medio Ambiente en la musealización del Centro de Recepción de Visitantes de Peña de Hierro, antiguo grupo pilones, proyecto que debe finalizarse para el segundo semestre de 2012 .

En síntesis este es el trabajo que ha permitido valorizar la mina de Peña de Hierro que ha recibido desde su apertura el 24 de octubre de 2004 la cifra de 512.337 visitantes.

La importancia del patrimonio de Peña de Hierro ha sido reconocido incoación de Bien de Interés Cultural con categoría de Zona Patrimonial, máximo nivel de protección que recoge la legislación andaluza en materia de Cultura (BOJA 222 de 11 de noviembre 
de 2011). La importancia medioambiental de Peña de Hierro ha sido reconocida primero con la declaración de Paraje Natural Protegido (Decreto de 14 de Diciembre de 2004, B.O.J.A. $\mathrm{n}^{\circ} 10$ de 11 de enero de 2005) y posteriormente implementada con la declaración de Monumento Natural de Andalucía (BOJA núm 49, de 12 de marzo de 2010).

Visitantes.

Gráfico 1 Evolución número de visitantes 1992-2011

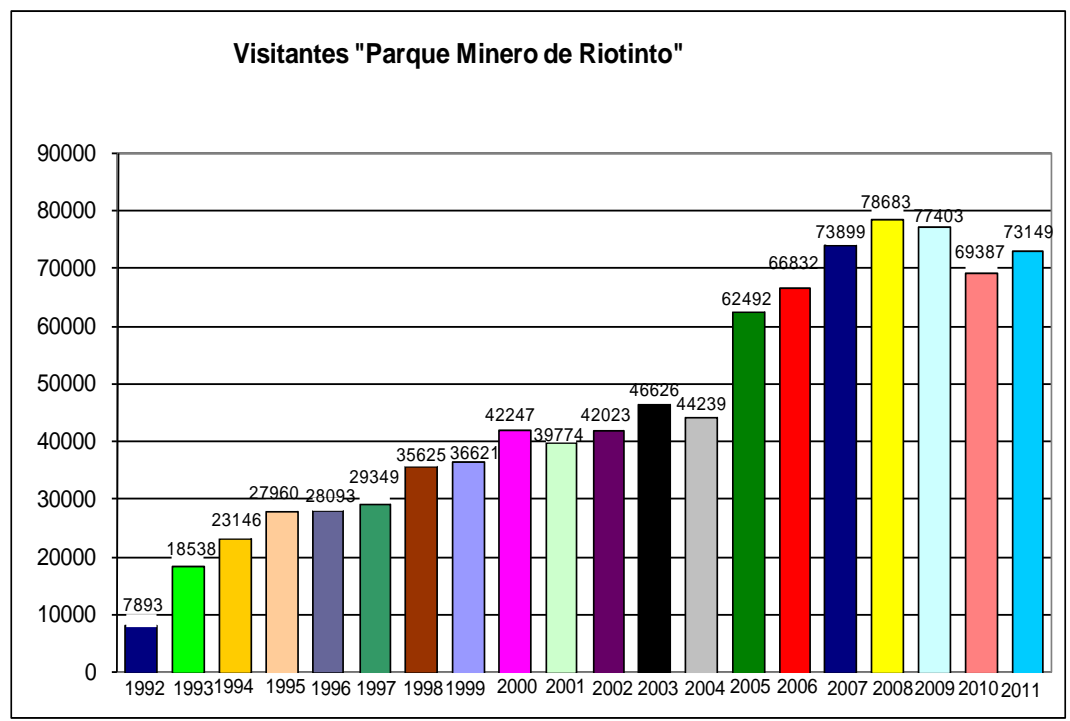

Desde la apertura en 1992 con un solo punto de visita, un tercio de la actual superficie del Museo Minero de Riotinto, hasta el año 2011 han visitado el Parque Minero 920.373 personas y la tónica ha sido ascendente con una media de 46.019 visitantes, se aprecia un aumento significativo a partir de 2005 que coincide con la apertura de dos de los cuatro puntos de visita actuales, Peña de Hierro el 24 de octubre de 2004 y la Casa $\mathrm{n}^{\mathrm{o}} 21$ el 27 de julio de 2005, siendo el año de máxima afluencia 2008 con 78.863 visitas, entre 2009 y 2010 se produjo una pérdida del $10 \%$ en el número de visitantes que explicamos por la alta pluviosidad del último trimestre y los primeros cinco meses de 2010, en 2011 se produjo una subida de 5\% en el número de visitantes con respecto a 2010, por lo que se ha recuperado la mitad de la afluencia perdida pues el período de lluvias en 2011 no retrajo tanto las visitas. La tendencia durante el primer trimestre de 2012 ha sido similar al año anterior. 
Gráfico 2 Visitantes del Parque Minero.

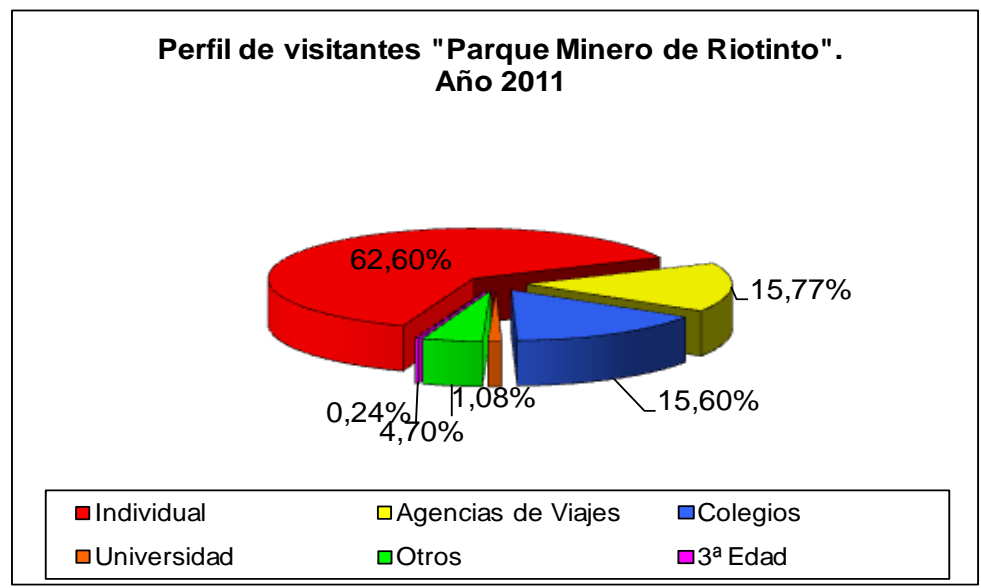

Entre los visitantes el grupo más numeroso es el individual-familiar con el 62,80 \% y es el target más interesante, pues es el que deja más valor añadido en la Cuenca Minera. También nos indica la organización propia del viaje y son principalmente visitantes alojados en la Costa y la Sierra de Aracena, destinos distantes entre sí a una hora y media y del que el Parque Minero de Riotinto está casi equidistante, o procedentes de las provincias limítrofes de Sevilla, Badajoz y en menor medida la propia provincia de Huelva.

El segundo colectivo en importancia con el 15,77 \% es el conformado por los viajes organizados por minorista y mayoristas procedentes de la provincia de Sevilla y de la costa de Huelva que vienen con el paquete completo de visita al Parque Minero (Museo Minero más Casa $n^{\circ}$ 21, Mina de Peña de Hierro y el Ferrocarril Turístico Minero), en este grupo cada vez están más presentes agencias de viaje especializadas en extranjeros comunitarios, principalmente alemanes y británicos.

El siguiente grupo es el educativo que supone un 15,60\%, y está compuesto por escolares desde infantil a secundaria, ha pasado de ser el 100 del tipo de los visitantes en los primeros años a establecerse en estas cifras estables y con poca variación. Este grupo se debe en gran parte a la labor divulgativa Fundación Río Tinto y la importancia didáctica que supone conocer de primera mano el conocer este itinerario turístico-cultural supuso que fuera declarado "Destino de interés preferente para todos los escolares por la Junta de Andalucía (Orden 15 de febrero 1.994). De este grupo el 70\% proceden de la Comunidad Autónoma Andaluza que con un acuerdo existente con la Consejería de Educación y el resto de las demás autonomías destacando Madrid, Cataluña y Extremadura. 
El cuarto grupo sería el integrado por universitarios que ha crecido mucho en los últimos años y de ser inexistentes han pasado a ser el 1,08\%, al ser un conjunto patrimonial considerado un complemento ideal en los viajes de estudios para diversas especialidades.

Por último la tercera edad cuando viajan en excursiones organizados representa el $0,24 \%$.

En cuanto al origen de los visitantes el $80 \%$ son nacionales, de los que el $40 \%$ son andaluces seguidos por las dos autonomías que más viajan por el resto de España, Madrid y Cataluña con un 18\% y $16 \%$ respectivamente y en cuarto lugar Extremadura que por proximidad con la Cuenca Minera de Riotinto supone el $12 \%$.

Los extranjeros suponen el 20\% de los visitantes, de los que el 99\% pertenecen a países de la Comunidad Económica Europea entre los que destacan con un 78\% alemanes y británicos y franceses, que por ese orden son los principales visitantes de la Costa de Huelva y Algarve, desde donde se desplazan al Parque Minero de Riotinto directamente o de paso hacia la Sierra de Aracena. En cuarto lugar por nacionalidades estarían los portugueses, que por proximidad suponen un 7\%, mientras que el resto de las nacionalidades comunitarias son casi residuales con un $2 \%$, al igual que las extracomunitarias con $1 \%$.

\section{Servicios, Infraestructuras y Equipamientos}

En 1992 cuando abrió el Parque Minero de Riotinto no existía en la Cuenca Minera de Riotinto ningún tipo infraestructura turística, salvo dos hostales en Riotinto y una pensión en Nerva. Actualmente hay diecisiete establecimientos turísticos con 160 habitaciones y 280 plazas. Dentro de la tipología de establecimientos el más numeroso son las Casas Rurales con un número de diez de las que la mayoría pertenecen de categoría básica. En segundo lugar se encuentran las pensiones con cuatro ejemplares, dos de ellas urbanas de las que dos se encuentran en Minas de Riotinto y además de los visitantes dan servicio a la población flotante hospitalaria. En tercer lugar estarían los hostales de los que hay dos y ambos en Riotinto también, actualmente uno está cerrado por reformas. Existen dos hoteles y sólo uno es de categoría media (tres estrellas), que está actualmente cerrado, el que está en funcionamiento está en Nerva con categoría de una estrella, por último existe un apartamento rural y un camping que disponía de 255 y está cerrado desde hace 16 meses. Visto todo lo anterior la oferta se concentra en los dos municipios con más población y actividad de la Cuenca Minera, Riotinto y Nerva, no existiendo ninguna infraestructura turística en la Granada de Riotinto (García y Delgado 2011, Pág. 474).

Los establecimientos de restauración en número de veinticuatro sólo tienen 
entre todos 1000 plaza, de todo punto insuficiente para atender la demanda, se concentran principalmente en Minas de Riotinto y en Nerva, y ninguno por si sólo puede dar cabida a dos autobuses o más durante todo el año, en verano se aumenta la capacidad con la posibilidad de emplear las terrazas pero en otoño e invierno o en días lluviosos esto no es posible.

A pesar de lo comentado en lo párrafos anteriores comienza a desarrollarse algunas iniciativas privadas mucho más interesantes como reconvertir la antigua Estación de Zalamea La Real del Ferrocarril Minero de Río Tinto en un restaurante y hostal o la reconversión de viviendas en el barrio de Bella Vista a alojamientos rurales.

Aunque en la Cuenca Minera de Riotinto existen dos oficinas de Información y Turismo en Nerva y en Zalamea la Real, a pesar de haber sido inauguradas nunca han funcionado como tal. Actualmente está en proyecto la apertura de la de Zalamea y una en El Campillo, pero la única instalación que ofrece hoy día información al visitante sobre que ver, donde comer y alojarse en la Cuenca Minera, la Sierra o la Costa de Huelva es la recepción del Museo Minero de Riotinto. (García y Delgado 2011, Pág. 475).

Una vez visto todo lo anterior podemos afirmar que la iniciativa de Fundación Río Tinto no se ha visto respaldada por un débil sector privado detectándose una escasez de emprendimiento, pues como se ha detectado en otras zonas aunque importante la iniciativa del turismo minero per ser no ha tenido la suficiente capacidad inductora en los servicios de apoyo al turista.

\section{CONCLUSIONES}

Tras veinte años desde la apertura del Parque Minero ha recibido 920.373 visitantes, se ha creado una infraestructura de servicio inexistente con anterioridad, aunque insuficiente todavía para cubrir la demanda de visitantes. Se han creado 35 puestos de trabajo directos y los indirectos se pueden multiplicar por tres, lo cual supone unos números de ocupación importante en una comarca con un 50\% de paro. Aunque a pesar de estos importantes resultados todavía estamos lejos aún de los logros conocidos en Reino Unido, Bélgica, Alemania o Polonia (Valenzuela et al., 2008, Pág. 232). 


\section{BIBLIOGRAFÍA}

Blanco, A. y Rothemberg, B. (1981): Exploración Arqueometalúrgica de Huelva. Barcelona, Río Tinto Minera S.A y Labor.

Barriga, F.J.A.S., Carvalho, D., Ribeiro, A. (1997) "Introduction to the Iberian Pyrite Belt”. En Barriga, F.J.A.S y Carvalho, D. (eds): Geology and VMS Deposits of the Iberian Pyrite Belt, SEG Neves Corvo Field Conference 1997, Guidebook Series, nº 27, pág 1-20. ISSN: 1885-7264

Cabello, F. J (2011): "Los programas formativos de empleo en la rehabilitación del Patrimonio Industrial”. En Pérez, J.A.; Delgado, A.; Pérez, J.M. y García, F.J. (Eds): Río Tinto, Historia, Patrimonio Minero y Turismo Cultural., Huelva, Universidad de Huelva y Fundación Río Tinto.

Delgado, A. (2007): “El Parque Minero de Riotinto”. En Fernández, R. (Coord.): Activos ambientales de la Minería Española, Madrid, Consejo Superior de Colegios de Ingenieros de Minas.

Delgado, A. (2009): Ferrocarril Turístico Minero, Huelva, Fundación Río Tinto.

Delgado, A. y Regalado, M.C. (2006): “Catálogo”. En Delgado, A. (Coord.): Catálogo del Museo Minero de Riotinto, Fundación Río Tinto, Sevilla, 197-238.

Delgado, A. y Regalado, M.C. (2009): “La Rehabilitación Patrimonial de la Mina de Peña de Hierro (Nerva, Huelva), Parque Minero de Riotinto (Huelva, España)”. En De Re Metallica n ${ }^{\circ} 12$, Sociedad Española para la Defensa del Patrimonio Geológico y Minero, pág. 55-63. ISSN 1577-9033 http:// www.sedpgym.es/descargas/Metallica/n12_55.pdf

Delgado, A. y Regalado, M.C. (2011a): "Museo Minero de Riotinto". En Pérez, J.A.; Delgado, A.; Pérez, J.M. y García, F.J. (Eds): Río Tinto, Historia, Patrimonio Minero y Turismo Cultural. Universidad de Huelva y Fundación Río Tinto, Huelva.

Delgado, A. y Regalado, M.C. (2011b): "Casa 21 de Bella Vista (Minas de Riotinto), Sección Etnográfica del Museo Minero de Riotinto". En Pérez, J.A.; Delgado, A.; Pérez, J.M. y García, F.J. (Eds): Río Tinto, Historia, Patrimonio Minero y Turismo Cultural. Universidad de Huelva y Fundación Río Tinto, Huelva. 
Fernández, R. (Coord.) (2007): Activos ambientales de la Minería Española, Consejo Superior de Colegios de Ingenieros de Minas, Madrid.

García, F. J. y Delgado, A. (2011): "Patrimonio y turismo en la Cuenca Minera de Riotinto”. En Pérez, J.A.; Delgado, A.; Pérez, J.M. y García, F.J. (Eds): Río Tinto, Historia, Patrimonio Minero y Turismo Cultural. Universidad de Huelva y Fundación Río Tinto, Huelva.

Gemio, G.; Fernández, F. y Rojano, P. (2006): “Geología”. En Delgado, A. (Coord.): Catálogo del Museo Minero de Riotinto, Fundación Río Tinto, Sevilla,35-40.

Harvey, C.E. (1981): The Río Tinto Company, an economic history of a leading international mining concern 1873-1954. Alison Hodge, Cornwall.

Leistel, J.M., Bonijoly, D., Braux, C., et al (1994). The massive sulphide deposits of the South Iberian Pyrite Province: geological setting and exploration criteria. Doc. BRGM nº 234, pág 236. ISSN: 007-6104

Llurdés, J. C. (1999): "Patrimonio industrial y Patrimonio de la Humanidad. El ejemplo de las Colonias Textiles Catalanas. Potencialidades turísticas y algunas reflexiones". En Boletín de la Asociación de Geógrafos Españoles, $n^{\circ}$ 28, pp. 147-160. ISSN 0212-9426.

Martínez, A. y Pérez, D. (1998): “El Patrimonio Industrial de la provincia de Alicante. Rehabilitación y nuevos usos". En Investigaciones Geográficas, nº 19 , Universidad de Alicante, Alicante. pág. 49-66.ISSN: 0213-4691.

Peñalver, M. T. (2004): "El turismo activo como alternativa y complemento al modelo turístico en la Región de Murcia”. En Cuadernos de Turismo, ${ }^{\circ}$ 14, Universidad de Murcia, Murcia. 179-215. ISSN 1139-7861

Pérez, J.A. (1996): Metalurgia extractiva prerromana en Huelva. Universidad de Huelva, Huelva.

Pérez, J.A. (1998): Las Minas de Huelva en la Antigüedad. Diputación de Huelva. Huelva.

Pérez, J.A.; Delgado, A. (2011): "Plata para las Águilas Imperiales”. Andalucía en la Historia, nº 53, pág. 329. 34-37. ISNN1695-1956.

Pérez, J. M. y Romero, E. M. (2008): Actuaciones sobre el patrimonio minero-industrial 
de la provincia de Huelva. Cuenca minera de Riotinto”, En Pasos. Revista de Turismo y Patrimonio Cultural, vol. 6, $\mathrm{n}^{\circ} 1$ Instituto Universitario de Ciencias Políticas y Sociales, Universidad de La Laguna, Tenerife, pp. 8396. ISNN -1695-7121.

Regalado, M.C.; Moreno, A. y Delgado, A. (2010): “Club Inglés Bella Vista Minas de Riotinto (Huelva)”. En De Re Metallica n ${ }^{\circ} 15$, Sociedad Española para la Defensa del Patrimonio Geológico y Minero, Madrid. pág. 43-56. ISSN 1577-9033

Sáez, R., Pascual, E., Toscano, M., Almodóvar, G.R. (1999) “The Iberian Type of volcano-sedimentary massive sulphide deposits”. Mineralium Deposita, 34:549-570. ISBN: 80-86406-27-X

Sáez, R., Almodóvar, G.R., Barriga, F.J.A.S. (1997) "Mineral exploration in the Iberian Pyrite” Belt. SGA News, 3: 1 and 7-10. ISSN: 1430-8665

Schermerhorn, L.J.G., (1971). An outline stratigraphy of the Iberian Pyrite Belt. Boletín Geológico y Minero $\mathrm{n}^{\circ}$ 82, Instituto Geológico y Minero de España, Madrid, pág. 239 - 268. ISSN 0366-0176.

Valenzuela, M.; Palacios, A.J.; Hidalgo, C. (2008): "La valorización turística del patrimonio minero en entornos rurales desfavorecidos. Actores y experiencias”. Cuadernos de Turismo, $\mathrm{n}^{0}$ 22, Universidad de Murcia, Murcia. 231-260. ISSN 1139-7861.

recibido 16/07/2012

aceptado 18/10/2012

arbitrado anónimamente 